\title{
A Study of Job Satisfaction and Retention Amongst Public and Private Basic School Teachers in Ghana
}

\author{
Emmanuel Adu-Baffoe \\ PhD Student, Institute for Educational Planning and Administration at University of Cape Coast, UNESCO \\ Category II Center of Excellence, Cape Coast, Ghana \\ E-mail of the corresponding author: eadubaffoestu.ucc@gmail.com \\ Solomon Bonney \\ PhD, Dean of Business Faculty, Laweh Open University College, Accra, Ghana
}

\begin{abstract}
The teacher is a focal point among the various agents of education who see to the advancement and development of a nation. This comparative study examined the job satisfaction and retention amongst basic school teachers at Ledzokuku Krowor Municipality in the context of Herzberg's Two Factor Theory. Specifically, the study will explore the impact of motivator and hygiene factors between public and private basic school teachers, identify the significant difference between public and private school teachers in their hygiene factors, measure the level of job satisfaction variables that are responsible to discriminate private and public school teachers and to find out factors of job satisfaction that influence teacher retention between public and private basic school teachers. The adapted version of Minnesota Job Satisfaction Questionnaire was used to collect quantitative data from 210 basic school teachers using descriptive statistics and inferential statistical techniques while the interviews conducted were analysed qualitatively through content analysis. For the qualitative data, 12 senior management teachers and those who indicated they were leaving or had left were purposely selected and interviewed in focus groups. Interviews were recorded using a digital voice recorder (Olympics VN-713PC) then translated verbatim. Interview transcripts were uploaded to NVivo10 software (QSR International Pty Ltd). Different codes were identified into potential themes and all important coded extracts were collated within the identified themes. The independent samples ttest results showed that there is a significant difference in job dissatisfaction variables of basic school teachers. High scores on salary, job security, policy, working conditions and low scores on status, relation with supervisors and subordinate are predictive of private schools teachers. This analysis suggests that private basic school teachers were more dissatisfied with their hygiene factors of job satisfaction than their counterparts in the public sector. It was recommended that the Ministry of Education and other stakeholders should develop a policy framework that will culminate into developing a Teacher Support and Motivation Framework (TSMF).
\end{abstract}

Keywords: Herzberg Theory, Hygiene Factors, Job Satisfaction, Motivator, Private and Public Basic School, Teachers, Retention

DOI: $10.7176 / \mathrm{JEP} / 12-3-16$

Publication date: January $31^{\text {st }} 2021$

\section{Introduction}

1.1 Introduce the Problem

The very survival of an organization depends on its capacity to recruit and retain qualified workers (Amoh \& Appiah-Brempong, 2017). The teacher is a focal point among the various agents of education who see to the advancement and development of a nation (Özcan, \& Koca 2019). The commitment and productivity of teachers depend not only on their quality but also on the satisfaction they get from the services they render. Private schools teachers are similarly important as their colleagues in the government funded schools hence the need for them also to be satisfied with their work (Manu et al., 2019). For about two decades now the establishment of educational institutes has witnessed increasing number. With the developing interest for quality teachers by school leaders and the recent phenomenon of poaching teachers from other schools, it has become expedient for school leaders to institute rewarding and job retention strategies to retain their teaching staff (Manu et al., 2019). Appropriate retention strategies will not only encourage teachers to put off their best for their students but also help in building a formidable cadre of well-trained human resource development for the country (Silva et al.,2019). It is imperative to take note that the vast number of these studies on job satisfaction and teacher retention was conducted in developed countries and therefore very hard to apply their outcomes to explain why Ghanaian teachers have been agitating for better conditions of services (Senyametor et al., 2019. Underlying elements of job satisfaction and retention in the Ledzokuku Krowor Municipality educational setting in Ghana appear not to be satisfactorily examined, however, the municipality has high concentration of basic schools, it is essential that these models of motivation be validated in an educational environmental setting in the Ledzokuku Krowor Municipality. The investigation sought to close this gap by validating Herzberg's Two Factor Theory for teachers in private and state funded school in the municipality. Disparities exist between state funded schools and private schools (Senyametor et al., 2019). 


\subsection{Importance of the Problem}

The Ghana Education Service (GES) and management of private basic schools regularly communicated disappointment about low efficiency of their staff which bring about adverse effect on teaching and learning. They often condemn the attitude of teachers who are lethargic, apathetic and indifferent to effective teaching and learning, not committed and are much of the time missing from work. (Amoako-Essien 2002). The government and different stakeholders in education regularly attribute their inability to achieve the desired results on the poor working attitudes of their staff (Azornu 2011; Amoako-Essien 2002). Therefore, the significant question to be posed and broadly be answered is whether school leaders and supervisors have put in place effective and efficient job satisfaction models and retention strategies that motivate their staff to be more productive (Shann, Rehman, Akhtar \& Zafar Riaz 2010). The absence of such motivation techniques leads to poorly motivated staff, high teacher attrition rate and low self-esteem (Goodman 2011). There is however, no reliable evidence to show that teachers in the school are pleased with their job and whether their job fulfilment has a perceived effect on job retention (Bennell \& Akyeampong 2007). Moreover, there seem to be little empirical research in employee job satisfaction in Ghana particularly in the Ledzokuku Krowor Municipality. The previous studies have concentrated on motivation of university academia and secondary school teachers (Oywak 2002). Despite these studies, there is a call for more investigation to test earlier findings in different settings at the Ledzokuku Krowor Municipality. Accessible literature concentrating on Maslow hypothesis has on several occasions been defective on the grounds of philosophy, methodology and hierarchy (Jones, 2005, Pinder \& Olan, 2012, Muaz \& Mahhem, 2012; Stello 2013). It is important that the Herzberg Two Factor theory be validated in an educational environment. This study will seek to close this gap by validating this conceptual framework. The mixed methodology approach is less represented in literature in respect of past research work. There have been most studies which skewed towards quantitative and qualitative methodology (Yin 2003). This current study adopted the quantitative and qualitative methodology approach to investigate the issues.

\subsection{Relevant Scholarship}

\subsubsection{Conceptual Framework}

The conceptual framework postulates that certain variables influence job fulfilment and dissatisfaction because they determine the level of job fulfilment and retention among teachers. According to Herzberg (1959) these factors are motivators and hygiene factors.In 2014, Abwalla (cited in McQueen \& Knussen 2002 p.7), independent variables could be described as are the antecedent factors or those factors that influence teachers' job fulfilment and retention. In this manner, independent variables are conceptualized as the hygiene and motivator factors whereas dependent variables is the outcome variable of the study. The dependent variables were job satisfaction, job dissatisfaction and enhanced job retention. Ssesanga \& Garrett (2005) claimed that issues often cited to have the tendency to produce negative effects and thus become dissatisfies are organizational policy and administration, technical supervision, salary, working conditions, job security and interpersonal relations. Many intellectuals and practitioners such as Spear et al. (2000); Sledge \& Coppage (2008); Hong \& Waheed (2011) on the other hand, issues cited often as producing positive effects on performance and hence considered as motivators include the work itself, achievement, and possibility of growth, advancement and responsibility. The Two-Factor theory noted that elimination of dissatisfies, which were maintenance or hygiene factors, did not necessarily raise individual performance. Thus, whereas poor working conditions for instance could be source of irritation to a worker and might make him buckle down, the correction of the situation will not really make him work more diligently although he will no longer feel dissatisfied. The individual will accept the correction as the way it should have been in the first place. The positive factors that Herzberg called satisfiers did motivate individuals to work harder. Herzberg, therefore, cited satisfies as the key motivators to improving job retention. 


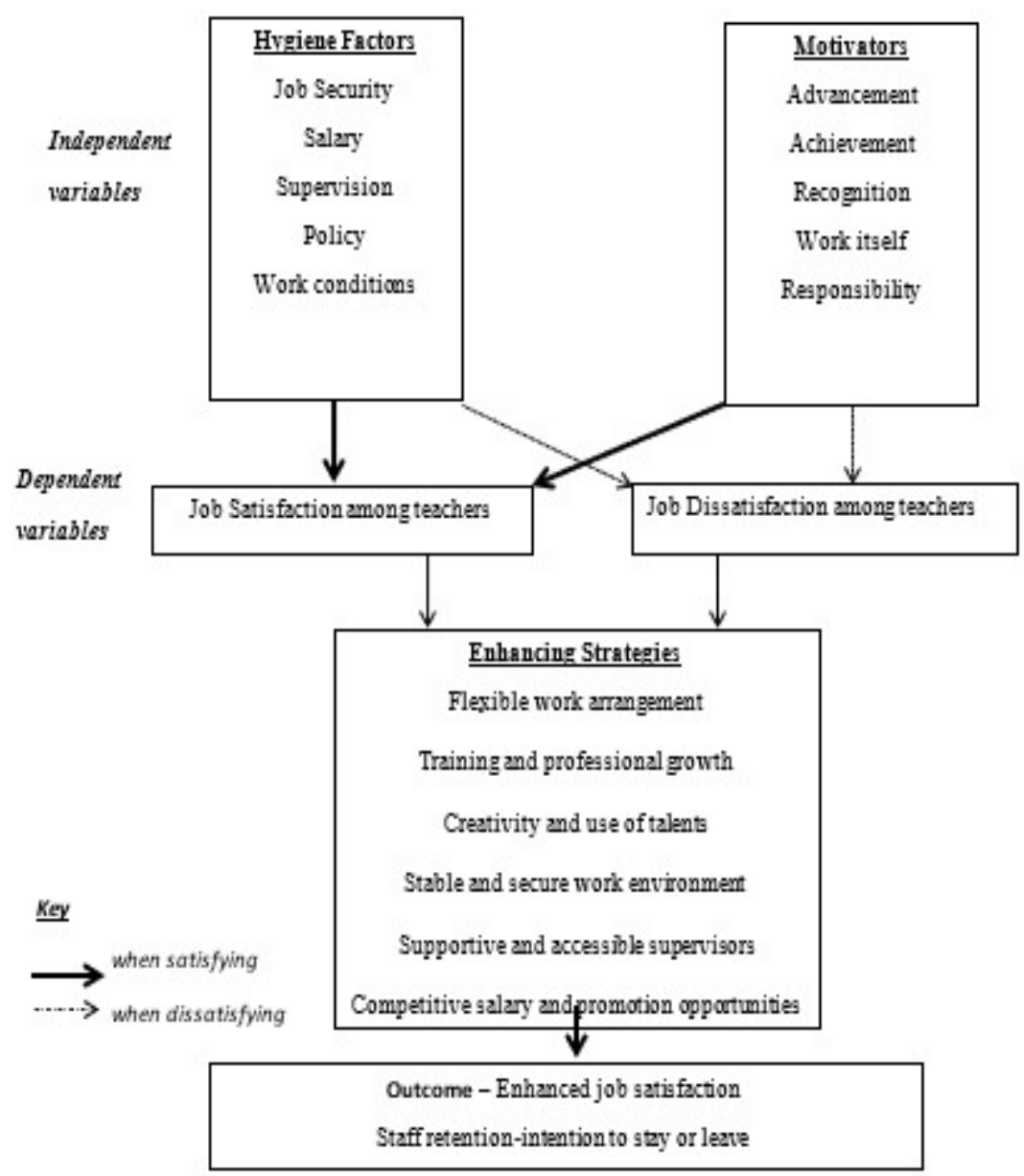

Figure 2.1: Conceptual Framework

Source: Stella (2013) modified Herzberg (1959)

\section{3,2 Justification for selecting Two-Factor Theory}

I planned to focus on Herzberg Two Factor model. The choice of this model was also prompted by its articulation of the relationship between intrinsic and extrinsic factors, which have an impact on an individual's motivation. George, et al. (2014) allude to attempts by Wall (2007) to draw out the connection between Maslow's theory of motivation and Two-Factor's exploration on hygiene and motivators. It is apparent that Herzberg's hygiene factors, which maintain performance, relates with Maslow's lower level needs. As indicated by Stello (2013), Maslow's model has received several criticisms on the grounds of philosophy, methodology and hierarchy. In 2010, Asare (cited in Afful-Broni p.100) revealed that in spite of many positive contributions to the work of administrators with their staff in the various organizations, Maslow's hierarchy of needs also suffers from certain setbacks. Herzberg's Theory with strongest support from empirical studies provides a quick understanding of intrinsic and extrinsic variables. Frederick Herzberg theory provided countless survey done in diverse circumstances. The studies further identified important empirical evidence about the two-factor theory; it very dynamic, universal, socially connected, meaning it does not concentrate on one group of culture and therefore universally accepted. The model has demonstrated to be useful instrument in the regular work of school executives and administration (Stello 2013). The Maslow model is too inflexible to explain the dynamic and unstable characteristics of needs. Herzberg's (1966) motivation-hygiene theory goes further to posit that factors intrinsic to work, such as achievement and responsibility, have more potential for a positive effect on motivation, while extrinsic factors, such as pay, managerial policy and working conditions have more potential to cause a negative effect if they fall below expectations. This makes the theory appear more applicable to education systems in which resources and expertise are abundant than to those in which they tend to be scarce. In the latter situation, improvement in pay or managerial policy can be important positive motivators; nevertheless, teachers in developing countries - indeed, in developed countries as well - are likely to be motivated by a mixture of intrinsic and extrinsic factors (Thant $\&$ Chang, 2020). In terms of its practical application to education systems, the first step in enhancing teacher 
motivation is to eliminate dissatisfaction; therefore, administrators should ensure that remuneration, working conditions, policy, administration and so forth are appropriate and reasonable. When these targets have been met, motivation itself can be addressed, but it should be borne in mind that a pay rise and improvement in working conditions alone rarely lead to a higher level of motivation; rather, administrators should seek to provide teachers with the opportunity for growth, achievement and greater responsibility (Amiri et al., 2020). The application of these theories in this study could be understood that, if teachers' "needs are satisfied", they can be motivated to do their job better (Thant \& Chang, 2020) and the reverse is possible.

1.3.3 Hygiene Factors

The two-factor theory postulated by Herzberg (1987), cited in Glickman, Gordon, and Ross-Gordon (2008) harmonizes with Maslow's hierarchy of needs theory. Based on extensive research over the years, there were positive factors that were quite distinct from negative factors that affected job performance and retention. According to Gibson (2000), these negative factors were called dissatisfies. Idris and Wan (2008) pointed out that issues often cited to have the tendency to produce negative effects and thus become dissatisfies are organizational policy and administration, technical supervision, salary, working conditions and job security. The Two-Factor theory has clearly shown that hygiene factors alone cannot create motivation, but they only prevent or reduce dissatisfaction and negative attitude towards work.

Job Security: The institution must promise workers of adequate job security in which the job accommodates a safe future. It leads to extraordinary dissatisfaction and lukewarm attitude if workers fear of being sacked (Matei 2004). Rynes and Minette (2004) postulated that a job with an abnormal state of employer stability to such an extent that an employee will have little possibility of being jobless. The condition of having a job secured is one that has a secured future imbedded in an agreement making dismissal difficult. Senol, et al (2003) contended that job security is an affirmation that a worker will maintain his job without the fear of losing it. It may stem from conditions of service, collective bargaining agreement or labour legislation.

Salary: Stello (2011) labelled salary as one component whose increase or diminishing reflects of job satisfaction and retention of an employee. They salary levels ought to be competitive, fair and encouraging. The salary should correspond to the cost of living otherwise it affects individual life (Matei \& Fataciune, 2004).

Working Conditions: There should be safety and a congenial environment at the work place. The work place should include satisfactory conditions such as modern and well maintained facilities. It also includes physical conditions that the employee experiences within the working environment for example heating, lighting, ventilation, number of students, the pleasantness of working condition, amount of work required, available amenities, noise, temperature, equipment, provision for leave such as annual, maternity leave (Stello, 2013).

Supervision: The supervisor or management must develop strategic plans and determine how the employees fit into the company's general plan. Otherwise the employees will be uncertain and therefore negative. The job of a supervisor requires high level of technical and conceptual skills to be a competent supervisor. The supervisor needs to be flexible because the job environment is constantly changing in order to promote and manage the company's ideals, policies, values and culture (Zeffane, 2010).

School Policy and Administration: School procedures and policies should be made flexible enough to promote compliance. They should be fair, capable of being enforced, must be applied to all equally. They should incorporate adaptable working hours, dress code, breaks, and vacations. It also represents a perception of an employee on whether the policies of a school in a good or bad, reasonable or not, and its influence level of satisfaction an employee experiences within the company (Stello, 2013).

1.3.4 Motivator Factors

Researchers for instance, Masud (2008) and Malik (2008) claimed issues cited as producing positive effects on performance and hence considered as motivators or satisfiers. According to Herzberg, motivator variables can bring about positive atmosphere and job fulfilment for an employee. These variables include growth opportunities, advancement, and responsibility.

Growth Opportunities: The employees should be bestowed with privileges to help them advance on their job which includes possibility of learning new skills and acquiring new knowledge. Not all employees want to advance to a higher level in the company. They prefer growth opportunities than advancement opportunities (Riley 2005). Advancement: There should be different growth strategies such as upward career progression plan and promotions. Hence, there should be opportunities to help employees to advance in the organization and a wellstructured promotional policies and plans. As a manager, you should be cognizant of the various elements of growth and advancement (Riley, 2005).

Responsibility: The managers should give them ownership of the job. The work environment should be devoid of strict and rigid supervision yet retain accountability (Stello 2013). It refers to the degree of freedom an employee has to make decisions on his own and implement new ideas.

Recognition: Colleagues and managers must applaud and recognise workers for their accomplishment. Recognition is always positive if it issued sincerely from people you trust and respect. Acknowledgement of employee's successful completion of work such as the way one is noticed after doing a job well done (Riley, 
2005).

Achievement: Employees must have the opportunity to accomplish a difficult job successfully typically by effort, courage, or skill. It also includes different feelings or situations which comprise successful or unsuccessful accomplishment of work, resolving certain problems and seeing the outcomes of one's efforts (Herzberg et al., 2000).

The Work Itself: The job task should be interesting and challenging for workers to ensure that they are able to accomplish. The job requires may require a number of complex high level skills. The practice or task required as well as the feelings related to the degree of routine and struggle of completing the task (Stello, 2013).

\subsubsection{Hygiene Factors: The Ghanaian Situation}

Idris and Wan (2008) pointed out that issues often cited to have the tendency to produce negative effects and thus become dissatisfies are organizational policy and administration, technical supervision, salary, working conditions and job security. The Two-Factor theory has clearly shown that hygiene factors alone cannot create motivation, but they only prevent or reduce dissatisfaction and negative attitude towards work. Most employees in Ghana like every other person is faced high dependency burden and this is attributed to high cost of living (Abotsi et al., 2019). It is not astonishing that the recent agitation that kept knocking on the doors of the National Labour Commission (NLC) in Ghana hinges on pay rates. A later work factor the NLC brought finality to was with teachers concerning their pay rates (Abotsi et al., 2019). Interest groups' including Ghana National Association of Teachers National Association of Graduate Teachers (NAGRAT) and Concerned Teachers Association (CTA) regularly embarks on strike actions as a result of pay issues. The high cost of living and high dependency burden (relatives) has created a situation where employees have made money a big matter in labour agitation (Abotsi et al., 2019). One can be right in recommending that the Ghanaian labourer ends up disappointed when commensurate pay is not gotten for work done. In 2010 the erstwhile National Democratic Congress government authorised the transfer of individuals of the security services (for example, the Ghana Police Service: GPO, Ghana Immigration and Fire Services) onto the Single Spine Salary Structure (SSSS) and there was increment in wages for most workforces. The new scheme was part of government efforts to restructure salaries and conditions of service to guarantee rationalization of pay for employees within the public sector. This has been because of the sloppy implementation which the Ghana Universal. Salary Structure (GUSS) failed to capture pay variations (Abotsi et al., 2019). Previously, employees resorted to strike, massive protest and other means to negotiate for better conditions of service; the implementation of the SSSS is believed to be fundamentally essential in dealing with issues with respect to pay disparities within public sector organizations in a study (Dartey-Baah \& Amoako, 2011). For instance, in July, 2014, the various teacher unions embarked on a strike action for considerable length of time demanding for better working conditions, stipends and with money being their major demands. These situations demonstrate that civil servant in Ghana is increasingly motivated by the hygiene variables in this case money. The scheme has generally received popular acclamation from public sector managers and employees. Other elements that influence workers is job security, a case of the hygiene conditions. Employees would regularly do everything conceivable to keep their employments (Dartey-Baah, \& Amoako, 2011). Often, workers are burdened with high cost of leaving and in that sense job security implies that their livelihood is dependent on it. Besides, the most common perception is that workers prefer securing employment in the state funded organizations than the private sector organization since they believe that long lasting work is not guaranteed (Salifu et al., 2018). Competition for trained career Ghana Education Service staff by private schools leads to GES victory in most places. Private schools retain teachers when they offer more than what the GES offers their staff in terms of salary, incentives, training and job enrichment, private schools are risky Change in the school at the death of the original owner leads to changes in staffing. In contrast, the Teacher's Union and state bureaucracy (GES) provides more security than the small private school). In contrast, teaching has now become a challenge in most privately-owned schools, there are more of such teachers who are uncertain where to begin and end their teaching career and therefore hop starting with different schools then to another, and along these lines; a destabilizing factor. Of late, privately owned basic educational institutes, have seen increase level of massive development in the hiring of new. More importantly, the biggest hurdle is maintaining these educators in the same individually managed schools till their retirement age. Majority of the educators have led to unstable practice where these teachers become displaced as they constantly change schools (Kumedzro \& Kwame-Felix, 2018). This is evident manifestation of the particular issues requiring attention in the privately-owned schools -explicitly, the ones identified with employment fulfilment. Job security and salary are two leading variables in Herzberg's theory and considering the Ghanaian experience, it isn't absurd to propose that hygiene variables plays a significant role in spurring workers in Ghana. Hence, it is worth stressing that workers appear to be increasingly worried about wages and job security and therefore the hygiene and motivator elements play a significant role in workers job satisfaction despite the fact that they might not be the prevailing factor in the Ghanaian context (Salifu et al., 2018).

1.3.6 The Motivators: The Ghanaian Context

Researchers for instance, Masud (2008); and Malik (2008) claimed issues cited as producing positive effects on performance and hence considered as motivators or satisfiers. According to Herzberg, motivator variables can 
bring about positive atmosphere and job fulfilment for an employee. These variables include growth opportunities, advancement, and responsibility, work itself, recognition. Ghanaian employees as well as those in different parts of the world desire fairness and equity in as better wages and employer stability, growth opportunities on the job, fascinating and interesting jobs, and greater responsibility and challenging jobs. In this way, the Ghanaian employee is spurred by the extrinsic elements as proposed in Herzberg's model. Cooperation and team work are credible factors seen to be very significant in setting up positive working environment in most institutions. This requirement for instance in GES and school administrators can be addressed by various organized groups within the teacher fraternity by organizing get together and field trips or by end of year school party through team dynamics (Peprah-Mensah, Adjei \& Adjei, 2017). Dartey-Baah and Amoako (2011) in a study concluded that combining the hygiene and motivator variables can bring about four situations to be specific;

High Hygiene/High Motivation: When there is high hygiene and motivation, it creates a good condition of happy employees where they are profoundly motivated and have couple of labour agitations.

High Hygiene/Low Motivation: Bored workers checking in for a Pay check. Workers have few grumbling complaints but are not exceptionally motivated.

High Motivation/Low Hygiene: In a situation where workers experience high motivation and low hygiene, they become motivated employees who admire the job however complaints a lot. In a circumstance where the job is energizing and challenging however pay and other conditions of service are not promptly accessible.

Low Motivation/Low Hygiene: Total chaos state of demotivated, despondent employees, the most noticeably terrible situation of demotivated workers with countless number of complaints.

1.3.7 Critique of Herzberg Two Factor Theory

Herzberg's theory is valued on the ground that it provides an insight into the task of motivation by drawing attention to the job factors which are often neglected by managers. It shows the value of job satisfaction and motivation. Thus, Herzberg's theory has solved the problems of managers who were wondering why their policies failed to motivate the employees adequately (Chu \& Kuo, 2015). However, this the theory has also not gone unchallenged. As Hur (2018) stated that Herzberg study overlooks situational variables. Herzberg's Two Factor theory assumed a connection between satisfaction and productivity despite the fact that one may dislike pat of his job. Ozsoy (2019) identified few weaknesses in Herzberg's Theory, one of which is the standardised scales of satisfaction. Herzberg did not take into account the various job factors that might cause satisfaction or dissatisfaction. As indicated by Jalagat (2016) some job factor scales are not purely motivation or hygiene factors. Herzberg used a general standardised scale, which may have caused errors in his findings. Apart from that, these unspecific job satisfaction scales are more likely to be a general morale survey, which means that they were not based on actual job experience or situation. The validity of the deductions drawn by Herzberg is also questionable. Herzberg failed to recognise the existence of substantial individual differences. Different individuals might have different needs and thus, different motivators. Keeping in view all these points I can conclude that Herzberg's theory has been widely read and accepted in literature. This theory provides valuable empirical evidence about the two-factor theory; it very dynamic, universal, socially connected, meaning it does not concentrate on one group of culture and therefore universally accepted.

1.3.8 Factors Contributing to Job Retention

Teachers occupy a crucial and indispensable position in the development process of nations including Ghana (Acheampong \& Gyasi, 2019). However, the greatest hurdle after recruitment and selection of teachers is their retention. Furthermore, money that employees receive for services rendered is important to them not financially for what it will but also psychologically for what it will provide in terms of status and recognition within and outside the organization Compensation, therefore, is a crucial component of employment and one of the most critical human resource coordination practices which involves their basic salary, bonuses, working conditions, promotions and recognition. The useful compensation principles start with ensuring fairness, equity in pay rates, regular salary administration, with its inherent practical transparency. Effective service compensation which is properly designed and equitable utilized is indeed of essence. This has to motivate teachers to perform their roles effectively in their schools. Social prestige, recognition and status are among what they expect to achieve in their place of work. In addition, Agyekum (2009) studied determinants of job retention among Ghanaian teachers in the Kumasi Metropolis. The study identified that even though there were some government-led strategies to enhance retention among teachers especially in under-resourced districts, these efforts were still inadequate. No wonder $75 \%$ of respondents indicated that they will not advise young people to pursue a career in teaching. A study by Acheampong and Gyasi (2019) indicated that sixteen variables that influence the retention of employees in the education sector which include job security, training and development, pay, recognition, working conditions, reward and recognition, career opportunities and promotion. Among them, security of jobs was the most significant element for retaining employees in the health service. Regardless of the field, a worker wants to know whether his/her conditions of service are comparable to other public sector workers who perform similar work and with the same qualification earning. Many teachers terminate their appointment due to reasons that include feeling 
unappreciated, excess workload, lack of feedback mechanism and loss of confidence in management. Job satisfaction will influence behaviour and increase their job retention.

1.3.9 Summary of Literature Findings and Gaps Identified

As Herzberg indicated in his model, it does not take only the motivators variables to completely motivate workers neither does it take the hygiene components to stop dissatisfaction. To motivate employees, supervisors and administrators need to strike a balance to identify the variables well suited to address the pressing needs of their employees. The study identified that money and job security are two major elements in Herzberg's theory and considering the Ghanaian experience, little consideration has been paid to the motivator's factors. The study also found limited literature concentrating on career choice and decisions to enter into practice, a basis upon perhaps a hybrid of retention and job satisfaction strategies which will include to a large extent range of extrinsic and intrinsic variables influencing teachers' job satisfaction and retention. The Herzberg two-factor model can culminate into developing a Teacher Support and Motivation Framework (TSME) for Ghana which is currently non-existent.

\section{Research Methods}

The mixed method approach was adopted to determine the job fulfilment and retention amongst teachers in the Ledzokuku Krowor Municipality. The study population included 210 state funded and private school teachers in the Ledzokuku Krowor Education Directorate. The combination of the qualitative and quantitative methods helps to understand the assumptions underlying each research method and provides strengths that offset the weaknesses of both quantitative and qualitative research. The philosophy underpinning of the study is pragmatism. This is because the study's epistemology, ontology and axiology are based on finding the most appropriate approach in answering the research objectives (Saunders Lewis \& Thornhill, 2009). With this philosophy, the study's ontology was based on the fact that answers provided for some of the objectives were based on the multiple views (realities). In other words, it accepts the independent views of the respondents (teachers and other stakeholders); whether it is their objective realities (positivism) or their socially constructed and subjective views (interpretivism). The epistemology of the study also admits that knowledge obtained from teachers and other stakeholders which was used to answer the research questions, was both objective and subjective. Based on this epistemology, the study used the most appropriate approach to solicit information from the respondents, whether through one or several sources. Specifically, the study allowed the use of personal interviews, structured questionnaires, and other secondary sources to solicit data to answer the objectives. The pragmatism stance of the study was also based on the axiology that value was placed on some of the views and perceptions of the respondents. This helped in presenting the best of answers to the questions the study raised in the researcher's view (Saunders et al., 2009).

\subsection{Research Design: Descriptive Survey}

Descriptive survey was adopted as a research design to provide a frame upon which data was gathered and analysed for the study. This type of research was considered contextually appropriate because it employed the combination of quantitative and qualitative data to effect analysis of results on the studied objectives (Ary, Jacobs and Razavieh 2002).The current study utilized the combination of qualitative (interviews) and quantitative (questionnaire) research methodological approach in collecting data. The combination of the two research approaches offer a good benefit on the study of which either could have on the work (Creswell \& Plano 2007). As quantitative techniques were dominant, and sequentially preceded the less-dominant qualitative techniques in this study.

\subsection{Participants and Sampling Procedures}

The Ledzokuku Municipality comprises twenty-four circuits. Out of the twenty-four circuits, five circuits were used for the main data collection namely Agbleza, Okpoi Gonno, Tsuibleoo South, Baatsona and Tsuibleoo Central (Ledzokuku Krowor Municipal Assembly, 2018). The target population (N) of this study included 341 basic school teachers from the five circuits of Ledzokuku Municipality. From which one hundred and eleven (111) were private school teachers and the remaining two hundred and thirty (230) were from public basic schools. The units of respondents were arrived at using multi-stage specific sampling techniques that were appropriate for the study. Therefore, the convenience sampling technique was employed to select five public schools from each of the five circuits and three private schools out of the five circuits, giving a total of forty (40) schools for the study. The desired sample size for this comparative study from the forty schools was drawn by implementing stratified random sampling techniques. Two hundred and thirty (230) teachers were chosen from twenty-five (25) public schools whilst one hundred and eleven (111) teachers were selected fifteen (15) private schools. The study also used purposive sampling to select 210 teachers, $152(72.4 \%)$ from public and $58(27.6 \%)$ from private schools who have had at least two years teaching experience in the municipality were targeted and answered the questionnaire. Those excluded were those who have worked in the schools for less than two years and those who did not consent to be part of the study. 
In the present study, the Minnesota Satisfaction Questionnaire was adapted to collect basic descriptive statistics from the respondents consisted of forty-five items using a 5-point Likert scale. It had forty-five job satisfaction and dissatisfaction statements. The motivator items had seventeen (17) intrinsic statements whereas the hygiene factors had twenty-eight (28) statements. The second instrument that was employed for data collection in the study is interview guide. The second instrument that was employed for data collection in the study is interview guide. The purposive sampling technique was employed to select twelve (12) interview participants based on two categories: (a) those who indicated they were leaving or had left (a) senior management teachers because in the context of the study their responses pertain to their experiences in the various schools to illicit responses about how they perceive the impact of the hygiene and motivator factors on their job retention inclination and their willingness to remain on the job till retirement or leave the teaching profession. The research instrument was subjected to a validity and reliability test. The original (MSQ) was modified with Cronbach's alpha of 0.77 was obtained as it was deemed appropriate for the selected sample. The adapted version contained 45 items. The data collected in the pre-test was analysed by using SPSS Statistics Software of version 20 to test for validity and reliability. Items that were not well understood by the respondents were reframed to make them clear. After the pilot testing, a Cronbach reliability co-efficient alpha of 0.916 was obtained as a measure of reliability using SPSS Statistics Software of version 20. The results obtained from the adopted test was reliable to be used for this study, since many experts in research methodology recommend a minimum $\alpha$ coefficient between 0.65 and 0.8 (or higher in many cases); $\alpha$ coefficients that are less than 0.5 are considered as unreliable. This meant that the instrument was internally consistent and was therefore appropriate for the study.

\subsection{Data Analysis}

The Statistical Package for the Social Sciences (SPSS) version 20 was used to analyse the data. The following techniques were employed during quantitative data analysis; descriptive statistics that is mean, standard deviation, Pearson Correlation, and variance of the respondents' scores in the questionnaire were computed. For hypotheses testing, quantitative data were collected, coded, tabulated, and analysed using inferential statistics. For the qualitative data, senior management teachers and those who indicated they were leaving or had left were interviewed in focus groups. Interviews were recorded using a digital voice recorder (Olympics VN-713PC) then translated verbatim. Interview transcripts were uploaded to NVivo10 software (QSR International Pty Ltd). Different codes were identified into potential themes and all-important coded extracts were collated within the identified themes.

\section{Results}

The five circuits of Ledzokuku Krowor Municipality employ totally three hundred and forty-one (341) teachers out of which two hundred and ten (210) participated in this research. A total of two hundred and ten (210) questionnaires were distributed. Out of the number, two hundred (200) questionnaires representing 95\% were duly completed and retrieved by the researcher.

3.1 Hypothesis 1 stated that there is a significant and positive relationship between each motivator factor and job satisfaction of basic school teachers in Ledzokuku Krowor Municipality.

In order to test the hypotheses that private and public school teachers were associated with statistically significant differences in motivator and hygiene factors. The Pearson's Correlation Coefficient, Independent t- test, discriminant functional analysis were tested and tabulated using variety of inferential statistical techniques.

Table 1:

Correlation Matrix Analysis Showing Significant and Positive Relationship between each Motivator Factor and Job Satisfaction

\begin{tabular}{lllllllll}
\hline & Variables & 1 & 2 & 3 & 4 & 5 & 6 & 7 \\
\hline 1 & Achievement & 1 & & & & & & \\
2 & Advancement & $.435^{* *}$ & 1 & & & & & \\
3 & Recognition & $.371^{* *}$ & $.336^{* *}$ & 1 & & & & \\
4 & Responsibility & $.183^{* *}$ & $.206^{* *}$ & $.286^{* *}$ & 1 & & & \\
5 & Possibility for personal growth & $.232^{*}$ & $.232^{* *}$ & $.280^{* *}$ & $.281^{* *}$ & 1 & & \\
6 & Work itself & .0 .08 & $.434^{* *}$ & $.280^{* *}$ & $.420^{* *}$ & $.420^{* *}$ & 1 & \\
7 & Job satisfaction & $.362^{* *}$ & $.339^{* *}$ & $.220^{* *}$ & $.242^{* *}$ & $.228^{* *}$ & $.433^{* *}$ & 1 \\
\hline
\end{tabular}

** Correlation is significant at the 0.01 level $(2-$ tailed $)$.

Source: Field data: May 2019

Table 1 indicates Pearson's Correlation Coefficient value higher than 0 (positive association) and close to 1 (perfect linear relationship). The analysis shows all motivator variables have a statistically significant positive relationship with job satisfaction $(p-$ value $=0.01)$. The null hypothesis 1 is therefore rejected as these results do 
not support it and alternative hypothesis 2 accepted that 'There is a significant and positive relationship between each motivator factor and job satisfaction of basic schools teachers in the Ledzokuku Krowor Municipality"'

3.2 Hypothesis 2 stated that there is no significant difference in job dissatisfaction variables of basic school teachers in Ledzokuku Krowor Municipality.

The independent samples t-test was used to establish whether significant difference exist between private and public basic school teachers in Ledzokuku Krowor Municipality in the mean values. Results obtained from this SPSS analysis are shown in the table 2 .

Table 2:

Results of Independent t-test analysis between private and public school teachers (Group Statistics)

\begin{tabular}{llllll}
\hline & High School & $\mathrm{N}$ & Mean & Std. Deviation & Std. Error Mean \\
\hline \multirow{2}{*}{ Job dissatisfaction } & Private Public & 53 & 3.5846 & .66571 & .04644 \\
& & 147 & 3.4164 & .49222 & .02729 \\
\hline
\end{tabular}

Source: Field data, May 2019

Table 3:

$\underline{\text { Results of Independent Samples t - test: Equality of Means }}$

\begin{tabular}{llll}
\hline & $\mathrm{t}$ & $\mathrm{df}$ & Sig (2 tailed) \\
\hline Job dissatisfaction & 3.107 & 198 & $\mathrm{p}>.002$ \\
\hline
\end{tabular}

Source: Field data, May 2019

A Levene's Test of equality of variance indicated the difference in mean value of 3.6 and 3.4 with a standard deviation of 0.6 and 0.5 for teachers in private and public basic school teacher in LKM. The test shows that there is a significant difference $(t=3.10, D f=198, p>.002)$. Therefore, such results provide enough justification to reject the Null hypotheses thus support alternative hypothesis or hypotheses two that 'There is a significant difference in job dissatisfaction variables of basic school teachers in Ledzokuku Krowor Municipality'. This analysis suggests that private basic school teachers were more dissatisfied with their hygiene factors of job dissatisfaction than their counterparts in the public sector. Working condition, job security and school policy and administration were possible reason for this result.

3.3 Hypothesis 3 stated that motivator and hygiene factors significantly explain the variance in job satisfaction of basic school teachers in the Ledzokuku Krowor Municipality

The next set of statistical analysis were carried out to find out if hygiene and motivator factors significantly explain the variance in job satisfaction of basic school teachers in Ledzokuku Krowor Municipality, multiple regression analysis was used and the results of the analysis are presented in Table 4 and 5 respectively.

Table 4:

Results of Multiple Regression

\begin{tabular}{lllll}
\hline Model 1 & R & R Square & Adjusted R Square & Standard Error of the Estimate \\
\hline 1 & .582 & .339 & .333 & 4.18076 \\
\hline
\end{tabular}

Source: Field data, May 2019

$\mathrm{R}=.582$

R Square $=.339$

Adjusted R Square $=.333$

a) Predators: (Constant), Achievement, Advancement, Recognition, Growth, Responsibility, Work itself, School Policy and Administration, Interpersonal Relationship with Supervisor, Salary, Working Condition, Interpersonal Relationship with Subordinates, Job Security, Status

Table 5:

Results of Multiple Regression - ANOVA

\begin{tabular}{|c|c|c|c|c|c|c|}
\hline \multicolumn{2}{|c|}{ Model 1} & Sum of Squares & $\mathrm{df}$ & Mean Square & $\mathrm{F}$ & Sig. \\
\hline \multirow{3}{*}{1} & Regression & 2069.669 & 2 & 1034.834 & 59.205 & .000 \\
\hline & Residual & 4037.596 & 231 & 17.479 & & \\
\hline & Total & 6107.265 & 233 & & & \\
\hline
\end{tabular}

Source: Field Data, May, 2019

a) Predators: (Constant), Achievement, Advancement, Recognition, Growth, Responsibility, Work itself, School Policy and Administration, Interpersonal Relationship with Supervisor, Salary, Working Condition, Interpersonal Relationship with Subordinates, Job Security, Status

b) Dependent Variable: Job satisfaction

Table 5 indicated that the coefficient administration $\mathrm{R}=.582$ which range is between 0 and 1 implies the joint 
effect of the independent variables is significant on the dependent variable (teachers job satisfaction) $(\mathrm{F}=59.205$. $\mathrm{df}=2,233)$ which is significant at $99 \%$. High $\mathrm{F}$ value means that there is more chance of rejecting the Null Hypotheses and that the Alternative since sig $=0.000$ it provides support for the Alternative that "Hygiene and Motivator factors significantly explain the variance in job satisfaction of high school teachers in Ledzokuku Krowor Municipality.

Table 6

Summary of Hypothesis Results

\begin{tabular}{ll}
\hline Hypothesis & Result \\
\hline $\mathrm{H}_{1}$ : There is a significant and positive relationship between each motivator factor and job & Supported \\
satisfaction of basic schools teachers in Ledzokuku Krowor Municipality.
\end{tabular}

$\mathrm{H}_{2}$ : There is no significant difference in job dissatisfaction variables of basic school teachers Not Supported in Ledzokuku Krowor Municipality.

$\mathrm{H}_{3}$ : Hygiene and Motivator factors significantly explain the variance in job satisfaction of Supported basic school teachers in Ledzokuku Krowor Municipality.

3.4 What are the factors of job satisfaction that influence teacher retention in a private/public school in Ledzokuku Krowor Municipality?

The results in this context entirely qualitative gathered through face-to-face interviews using an interview guide were transcribed, response data and notes were analyzed according to the content. Different codes were identified into potential themes and all-important coded extracts were collated within the identified themes.

Table 7: Themes, Sub-Themes and Codes for Factors Contributing to Job Retention

\begin{tabular}{|c|c|}
\hline Theme & Codes \\
\hline \multirow[t]{7}{*}{ Factors Contributing to Job Retention } & Adequate remuneration \\
\hline & Job security \\
\hline & Social prestige \\
\hline & Improved conditions of service \\
\hline & Equity in pay rates \\
\hline & $\begin{array}{l}\text { Teachers participation in educational } \\
\text { policies }\end{array}$ \\
\hline & $\begin{array}{l}\text { Adequate facilitates for enhancing } \\
\text { teaching and learning }\end{array}$ \\
\hline
\end{tabular}

Source: Field Data, May, 2019

Teachers had a fair idea of the factors that will contribute to their willingness to remain on the job till retirement age. Teachers confidently informed us that adequate remuneration, job security, social prestige, improved working conditions, equity in pay rates, adequate facilitates for enhancing teaching and learning would have changed their decision concerning their retention or stay in the teaching profession.

A junior high school science teacher explained:

I am not satisfied with my take home salary which cannot take me home. Inadequate salary and lack of proper remuneration can affect my job retention. As a novice teacher, up till now, I have not been paid my salary arrears since last academic year. Sometimes I regret choosing this job because of low levels of salary structure has reduced the prestige attached to the teaching profession (J. Abban, personal communication, July, 2019)

Another matured aged science teacher recommended that:

Conditions of service should be improved to make the teaching profession attractive. The single Spine Salary Structure is nothing to write home about. A useful remuneration starts with ensuring fairness, equity in pay rates. Social prestige, recognition, better incentives and status are among what I expect government for that matter GES to consider doing for us to continue on this job till retirement ( $\mathrm{R}$. Simpson, personal communication, July, 2019).

A statement by another teacher hinted that:

Indeed, GES has not done enough with our remuneration as reflected in our levels of salaries and fringe benefits. Inadequate salary and lack of proper remuneration can affect my job fulfilment and my decision to quit the teaching profession. You see...... the general distortions in our conditions of service have eroded my confidence in the teaching job. I will leave for another sector if I get the opportunity (C. Nyamekye, personal communication, August, 2019).

As another teacher recounted that:

Sometimes we wake every day and new policies are implemented without our inputs as demonstrated in decision making. You see my friend no educational policy can succeed without the active participation of 
teachers. There is a new curriculum which GES will start implementing in September this year without our inputs. The way school policies are put into practice is very disturbing. Typically, we are not invited to participate in school board meetings and supervisors meeting (H. Sagoe, personal communication, August, 2019).

Additionally, another staff remarked that:

Teachers should be involved in the policy formulation and implementation process. We are often ignored in the policy making process in terms of our conditions of service and financial incentives for us. This aspect has not influenced me to stay (O. Bui, personal communication July, 2019).

Job security and working conditions are a major cause of considerable concern to private school teachers. A consistent complains is lack of comprehensive and codified conditions of service of service as exemplified in the extract below by one teacher:

I am afraid I can lose my job anytime even after serving the school for more than ten years. There is no security of jobs when the school proprietor passed on last year and another care taker took over the school administration and one minor mistake can be a last day of your work (O. Sarah, personal communication. July, 2019).

This perspective was confirmed by another teacher who sounded demotivated:

I have no written and documented working conditions. There is no provision for leave study leave, annual leave, promotions and maternity leave. I am not happy with the pleasantness of working condition and the workload at my disposal. Sometimes, I don't get time to accomplish my domestic obligations (G. Adjei, personal communication, August, 2019).

This perspective was confirmed by another teacher who sounded demotivated:

I have no written and documented working conditions. There is no provision for leave study leave, annual leave, promotions and maternity leave. I am not happy with the pleasantness of working condition and the workload at my disposal. Sometimes, I don't get time to accomplish my domestic obligations (E. Omane, personal communication, August, 2019).

Another teacher revealed that:

There are inadequate facilitates for enhancing teaching and learning. The physical state of the classrooms is poor. We have no electricity, library, ICT and science lab for practical lessons and these services need to be addressed as a matter of urgency. Sometimes it is not all about money but if these facilities are not available, we become ineffective and inefficient in our job as teachers (F. Attaquah personal communication, August, 2019).

Another participant said:

We don't have proper furniture. The physical state of the classrooms is very appalling with the floors full of holes and the ceiling broken beyond repairs. In the raining season the children are crowded in a dilapidated classroom (A. Agbo, personal communication, August, 2019).

An English Language teacher with ten years' experience mentioned that:

I am currently pursuing an MBA programme and my goal right now is to work for an organization where I can build a career. I would like to assume more management responsibilities in the banking sector within the next decade. The banking sector maintains high level of prestige and status and therefore respected and admired. The financial incentives attached to this job as a public school teacher is not rewarding. This aspect has not influenced me to stay (N. Ashokor, personal communication, August, 2019).

\section{Conclusion}

With regards to the six motivators factors of job satisfaction, recognition, responsibility and work itself, the analysis shows all motivator factors have a statistically significant positive relationship with job satisfaction. Public school teachers expressed greater dissatisfaction with hygiene factors such as salary, working conditions and school policy and administration. Private school teachers were more dissatisfied with their hygiene factors of job satisfaction than their counterparts in the public sector. Working condition, job security and school policy and administration were reason for this result. The results also indicated that almost all discriminant scores of the public schools lay on low scores while discriminant scores of private basic school teachers shows high scores for motivator variables. High scores on salary, job security, policy, working conditions and low scores on status, relation with supervisors and subordinate are predictive of private schools teachers. The interviewees ranking of job retention factors that contribute to teachers willingness to remain in the public sector ranked salary, working conditions, prestige and cooperative school policy and administration are indicative of public sector teachers interviewed. Private basic school teachers indicated there were dissatisfied with job security, lack of promotion and working conditions will contribute to their willingness to remain on the job till retirement. 


\section{Discussion and Implications}

The independent samples t-test results showed that there is a significant difference in job dissatisfaction variables of basic school teachers. High scores on salary, job security, policy, working conditions and low scores on status, relation with supervisors and subordinate are predictive of private schools teachers. This analysis suggests that private basic school teachers were more dissatisfied with their hygiene factors of job satisfaction than their counterparts in the public sector. The contribution of this research to knowledge among others can be viewed along the accompanying strands: clarification of the literature and methodology. practice, policy

\subsubsection{Research}

This study also contributes to a clarification of the literature and methodology, which can be useful for future studies on teacher motivation and to stimulate thinking about teacher motivation, drive policy development, and energize the implementation of a national teacher motivation strategy in a systematic, pragmatic and sustainable manner. This study, therefore, aims to form a foundation for the construction of a knowledge base in terms of policy changes designed to improve teacher motivation in Ghana. In order to facilitate quality teaching and learning, teachers need to be supported and motivated. Understanding the triggers for teacher motivation is key to attracting and retaining teachers in the profession and an important component of building positive teaching and learning environments at the school level.

5.1.2 Policy

The findings of this study strengthened and confirmed existing information through the use of new arguments. In terms of policy, it is important to understand that the Maslow model is not culture bound. As such, it may not be effective in non- Western contexts such as Ghana as literature critically gives a more rounded and research based picture of the effectiveness of the Herzberg Two Factor Theory. At best, the results of the study provided a basis upon perhaps a hybrid of motivator and hygiene variables which the Ministry of Education, Ghana Education Service, Ghana Association of Private Schools and Teacher Unions can consider with the definitive objective of developing a Teacher Support and Motivation Framework (TSME) where there seem to be little empirical literature. The effectiveness of a strategic intervention like a Teacher Motivation Framework is increasingly judged on the basis of effective learning outcomes which the Herzberg's Two Factor Theory lend credence to.

5.1.3 Practice

From a practice perspective, this study provided detail guidelines to the major partners of Ministry of Education, Ghana Education Service and Ghana National Association of Private Schools in distinguishing motivational variables, social and work-related factors impacting teacher's retention. To this end, it is imperative to understand what attract teachers in and what conditions are essential for their engaged persistence and retention. The quality of the student's learning outcomes and knowledge assimilation is greatly improved by the level of teacher dedication and motivation.

\section{References}

Abotsi, A. K., Dsane, C. F., Babah, P. A., \& Kwarteng, P. (2019). Factors influencing the choice of teaching as a career: an empirical study of students in colleges of education in Ghana. Contemporary Social Science, 115.

Acheampong, P., \& Gyasi, J. F. (2019). Teacher Retention: A Review of Policies for Motivating Rural Basic School Teachers in Ghana. Asian Journal of Education and Training, 5(1), 86-92.

Amoh, I., \& Appiah-Brempong, E. (2017). Prevalence and risk factors of obesity among senior high school students in the Adansi North district of Ghana. International Journal of Community Medicine And Public Health, 4(10), 3762-3769.

Amiri, E., Heidari, K., Khezri, A., Imani, A., \& Faraji-Khiavi, F. (2019). A survey of job satisfaction among staff of Jundishapur medical teaching hospitals in Ahvaz; based on Herzberg's two-factor model. Depiction of Health, 8(1), 3-10.

Amoah, S. A. (2019). Situational Analysis of Labour Turn Out in the Ghanaian Education Sector: The Strides and Preferences. International Journal of Asian Social Science, 9(9), 491-507.

Chu, H. C., \& Kuo, T. Y. (2015). Testing Herzberg's two-factor theory in educational settings in Taiwan. The Journal of Human Resource and Adult Learning, 11(1), 54-65.

Dartey-Baah, K., \& Amoako, G. K. (2011). Application of Frederick Herzberg's Two-Factor theory in assessing and understanding employee motivation at work: a Ghanaian Perspective. European Journal of Business and Management, 3(9), 1-8.

George, L. A., Benon, C. A., Babah, P. A., \& (2014). Herzberg's theory of motivation: Practical Assessment Abstract International http://www.interwork/projects/par.html

Glickman, F., Gordon, B., \& Ross-Gordon. (2008). Validating the two-factor theory on Job dissatisfaction among Queb State Region Schools. National Centre for Educational Statistics, 34(3): 233-258.

Gibson, J. A., (2000). The Psychology of Organisations behaviour Structure processes ( ${ }^{\text {th }}$ ed.). New York: McGraw-Hill. 
Herzberg, F., Mausner, B. \& Snyderman, B., (2000). The motivation to work. New York: John Wiley and Sons.

Hur, Y. (2018). Testing Herzberg's two-factor theory of motivation in the public sector: is it applicable to public managers?. Public Organization Review, 18(3), 329-343.

Idris, A. A. \& Wan, F. (2012). Does motivational factor influence job retention and effectiveness? A review of literature. Journal of Business Management and Finance 3(1), 1-9.

Jalagat, R. (2016). Job performance, job satisfaction, and motivation: A critical review of their relationship. International Journal of Advances in Management and Economics, 5(6), 36-42.

Kotni, V. D. P., \& Karumuri, V. (2018). Application of Herzberg two-factor theory model for motivating retail salesforce. IUP Journal of Organizational Behavior, 17(1), 24-42.

Kumedzro, F. K. (2018). Teachers' Perception of Job Satisfaction and Retention in Ghana: Perspectives from Special Needs Educators. African Educational Research Journal, 6(4), 262-268.

Ledzokuku Krowor Municipal Assembly (2018). Medium and long term report, FOAT assessment initiative. Techiman: Author.

Ledzokuku Krowor Municipal Assembly (2018). Medium and long term report, FOAT assessment initiative. Ledzokuku: Author.

Manu, B. D., Zhang, H., Oduro, D., Krampah-Nkoom, A., Mensah, I. A., Anaba, O. A., \& Isaac, A. (2019). School Board Efficiency in Financial Management and Human Resource in Public Senior High Schools: An Evidence from Ashanti Region, Ghana. International Journal of Social Science Studies, 8(1), 79-89.

Matei, A. \& Fataciune, M., (2004). Job satisfaction of public and private

workers in Romania. Proceedings of the 12th International Conference on Business Development Studies (IICBA`16, Barcelona. https://papers.ssrn.com

Matei, A. Rynes, L. \& Minette, K. (2004). The Importance of Compensation Schemes on Employee job Motivation: Human Resource Management (Vol 53, No 5, pp. 441 - 449). http://citeseerx.ist.psu.edu.

Malik, M. E., \& Masud, B., (2008). Towards understanding controversy on Herzberg's motivation. European Journal of Business and Management 3 pp. 258 - 266.2(11), 939-41.

Nyarko-Sampson, E., Amponsah, M. O., \& Asamani, L. (2019). Person-Environment Fit and Turnover Intentions of Senior High School Teachers in Ghana. International Journal of Education \& Psychology in the Community, 9.

Ngimbudzi, F. (2009). Job satisfaction among basic school teachers in Tanzania: The case study of Njombe District (Unpublished Master's Thesis). University of Jyvaskyla.

Özcan, H., \& Koca, E. (2019). The Impact of Teaching the Subject

"Pressure" with STEM Approach on the Academic Achievements of the Secondary School 7th Grade Students and Their Attitudes Towards STEM. Egitim vBilim, 44(198).

Ozsoy, E. (2019). An empirical test of Herzberg's two-factor motivation theory. Маркетинг і менеджмент інновацій, (1), 11-20.

Pepra-Mensah, J., Adjei, L. N., \& Agyei, A. (2017). Effect of

compensation on basic school teachers' job satisfaction in the northern zone: The case of Ghana. Global Journal of Management and Business Research.

Riley, N.R (2005). Aggregate and individual predictability of the Two - Factor Theory of Job Satisfaction. Personnel Psychology 23 (1) pp. $55-66$.

Rynes, I. \& Minette, A., (2002). Motivation-Hygiene Theory: Applicability on Teachers. The Journal of Educational Research pp. 39-47.

Salifu, I., Alagbela, A. A., \& Gyamfi Ofori, C. (2018). Factors influencing teaching as a career choice (FIT-Choice) in Ghana. Teaching Education, 29(2), 111-134.

Saunders, M., Lewis, P., \& Thornhill, A. (2009). Research Methods for Business Students (5th ed.). Essex: Pearson Education Limited.

Senol, F., (2003). The Impact of Job Security on the Perception of Staff in Hospitality Business Journal of Economic and Social Studies. Retr http://eprints.ibu.edu.ba.

Silva, M. R. A., de Amorim Carvalho, J. C., \& Dias, A. L. (2019). Determinants of Employee Retention: A Study of Reality in Brazil. In Strategy and Superior Performance of Micro and Small Businesses in Volatile Economies (pp. 44-56). IGI Global.

Sanjeev, M. A., \& Surya, A. V. (2016). Two factor theory of motivation and satisfaction: An empirical verification. Annals of Data Science, 3(2), 15-24

Thant, Z. M., \& Chang, Y. (2020). Determinants of Public Employee Job Satisfaction in Myanmar: Focus on Herzberg's Two Factor Theory. Public Organization Review, 1-19.

Senyametor, F., Minadzi, V. M., Dankyi, L. A., \& Maison, R. S. (2019). Relationship between Teacher Job Satisfaction and Productivity in the Asante Akim South District of the Ashanti Region of Ghana. Journal of Education and Learning, 8(3), 193-201.

Stello, C. M., (2013). An empirical review of Herzberg's two-factor theory of job satisfaction: Documents Analysis 
review. University of Pennsylvania, http//: www.upsn.umb.edu.conf/2013

Stello, C. M., (2011). Two Factory Theory of Herzberg's job satisfaction: Review of Related Literature. University of Minnesota. http//: www.cehd.umn.edu/01opd/research/student conf/2019

Wall, T., (2007). Herzberg's two - factor theory of job satisfaction: A critical evaluation and some fresh evidence. Industrial Relations Journal 2 pp. $21-45$.

Zeffane, R., (2010). Leadership of Trust Towards a two-factor theory: A focus on trust in leadership. Retrieved on July, 2, 2019 from http:/go.galegroup.com.ezproxy.sckans.edu/ps/. 